Available online at GSC Online Press Directory

GSC Biological and Pharmaceutical Sciences

e-ISSN: 2581-3250, CODEN (USA): GBPSC2

Journal homepage: https://www.gsconlinepress.com/journals/gscbps

(RESEARCH ARTICLE)

\title{
Asymptomatic malaria and its effect on parturients who received intermittent preventive treatment, a cross sectional study of the Bekwai District Ghana
}

\author{
Asamoah Gideon Darko 1, 4*, Adoba Prince 1, Edzeamey Fred Jonathan 2, Ephraim Richard KD ${ }^{1}$, Sampong \\ Bernard Berko ${ }^{2}$, Gborgblorvor Delphine ${ }^{3}$, Wiredu Osei Kwame ${ }^{2}$ \\ ${ }^{1}$ Department of Medical Laboratory Sciences, School of Allied Health Sciences, College of Health and Allied Sciences, \\ University of Cape Coast, Ghana. \\ ${ }^{2}$ Laboratory Department, Bekwai Municipal Hospital, Ashanti-Bekwai, Ghana \\ ${ }^{3}$ Out-Patients' Department, Bekwai Municipal Hospital, Ashanti-Bekwai, Ghana \\ ${ }^{4}$ Laboratory Department, Akomaa Memorial SDA Hospital, Ashanti-Bekwai, Ghana
}

Publication history: Received on 25 June 2018; revised on 07 July 2018; accepted on 13 July 2018

Article DOI: https://doi.org/10.30574/gscbps.2018.4.2.0054

\begin{abstract}
Malaria is preventable but has contributed significantly to maternal morbidity and mortality in our environment. Malaria parasitaemia during pregnancy is mostly asymptomatic, untreated but with complications such as low birth weight. This cross-sectional study examined the prevalence of asymptomatic malaria and its effects among parturients who had received intermittent preventive treatment in pregnancy. One hundred (100) parturient who had received sulphadoxine pyrimethamine (SP) for intermittent preventive treatment in pregnancy (IPTp) were conveniently recruited from the Bekwai Municipal Hospital and Akomaa Memorial SDA Hospital onto the study. Blood sample was collected from each participant for the detection of malaria parasitaemia, and estimation of haemoglobin concentration. A well-structured questionnaire was used to obtain socio-demographic and clinical data of participants. The prevalence of malaria among pregnant women in this study was 19\% when both RDT and microscopy were used. Anaemia was present in $27 \%$ of the participants, with $14 \%$ giving birth to children with low birth weight. Most of the participants with malaria parasitaemia were primiparous, primigravida and not using insecticide treated nets (ITN). Half (50\%) of participants with severe parasitaemia gave birth to children with low birth weight. Birth weight was associated with severity of parasitaemia $(\mathrm{P}=0.029)$. Multigravida were more likely to give birth to children with low birth weight. The prevalence of malaria among parturient who had received IPTp is still high, and severe malaria was associated with low birth weight. Pregnant women should be educated on the need to use ITN since they are more prone to malaria infection.
\end{abstract}

Keywords: Malaria; Pregnancy; Parturient; Intermittent preventive treatment in pregnancy (IPTp); Sulphadoxine pyrimethamine (SP); Low birth weight

\section{Introduction}

Malaria is a parasitic disease of humans especially in the sub-Sahara, where about $90 \%$ of global deaths due to malaria occur [1]. Most malaria infections, and the most severe morbidity and mortality, are caused by Plasmodium falciparum which is the most common parasite in Ghana and sub-Saharan Africa [2]. Most P. falciparum infections occur in subSaharan Africa, and the parasite has been shown to be more common in pregnant than non-pregnant women. It also has a substantial adverse effect on pregnancy outcome [3]. Miscarriages, stillbirths, preterm births intra-uterine growth retardation are common in pregnant women with malaria [4]. Low birth weight is the single greatest risk factor for neonatal and infant mortality [5]. Analysis of cross-sectional data on birth weight and survival from five sites in sub-

\footnotetext{
${ }^{*}$ Corresponding author

E-mail address: gdk.asamoah@gmail.com
}

Copyright (C) 2018 Author(s) retain the copyright of this article. This article is published under the terms of the Creative Commons Attribution Liscense 4.0. 
Saharan Africa showed that infant mortality is three times higher for low birth weight babies than for those of normal weight.

Despite numerous studies, and control and prevention strategies, malaria in pregnancy still remains an important public health problem. In Ghana, the National Malaria Control Programme (NMCP) led the development of a revised National Strategic Plan in 2008 which called for a reduction in malaria disease burden (morbidity and mortality) of $75 \%$ by the year 2015 using 2006 as the baseline. The primary interventions included early diagnosis with prompt and effective treatment of malaria with ACTs, scaling-up vector control measures emphasizing universal ITN coverage, targeted indoor residual spray (IRS) application in selected areas and intermittent preventive treatment in pregnant women [6].

Intermittent preventive treatment in pregnancy (IPTp) involves the administration of a curative treatment dose of an effective antimalarial drug, sulphadoxine pyrimethamine (SP), at predefined intervals during pregnancy, beginning after quickening in the second trimester [7]. The use of intermittent preventive treatment during pregnancy (IPTp) eliminates malaria parasites and prevent their accumulation in the placenta [7]. Also, high coverage of IPTp showed a reduced risk in maternal anemia and low birth weight [8]. This study sought to examine the prevalence of asymptomatic malaria parasitaemia among parturients who had received intermittent preventive treatment in pregnancy at Bekwai in the Ashanti Region of Ghana.

\section{Materials and methods}

\subsection{Study site}

This cross-sectional study was conducted from January to May, 2016 at Bekwai in the Ashanti Region of Ghana. Bekwai is the capital and the largest in the Amansie community, located in the rainforest zone of West Africa with a population estimated to be 131,291 inhabitants. The climatic conditions of Bekwai are typical of that of a tropical region and therefore aid malaria transmission. The Municipal is principally urban. There is, however, rural communities around the area with farming as their main occupation.

\subsection{Study participants}

A total of 100 parturient were conveniently recruited from the Bekwai Municipal Hospital and Akomaa Memorial SDA Hospital onto the study. All pregnant women presenting in labour at term within the study period who have received at least two doses of sulphadoxine pyrimethamine (SP) for intermittent preventive treatment in pregnancy (IPTp) were included in the study. Pregnant women who were symptomatic (chills, fever, nausea, rigor, vomiting, headache), had antepartum heamorrhage, and hypertension in pregnancy were excluded.

A total of 100 parturients in labour were recruited for the study using convenient sampling technique. Sample size was calculated using the formula;

$$
n=\frac{t^{2} \times p(1-p)}{m^{2}}
$$

Where, ' $t$ ' is the confidence level at 95\% (standard value of 1.96)

' $\mathrm{p}$ ' is the estimated prevalence

' $m$ ' is the margin of error at $5 \%$ (standard value of 0.05 )

\subsection{Questionnaire administration}

A well-structured pre-tested questionnaire was used to obtain information on demographic and clinical variables such as; age, occupation, education level, gestation age (weeks), parity, and Gravida, use of ITN, doses of SP previously given at ANC from each participant.

\subsection{Blood sample collection}

About three (3) milliliters (ml) of venous blood sample was collected from each participant and dispensed into a $\mathrm{K}_{2}$ EDTA tube for detection of malaria parasites and estimation of hemoglobin concentration. 


\subsection{Diagnosis of malaria}

\subsubsection{RDT}

A rapid diagnosis test (RDT) for identification of malaria parasite histidine-rich protein II (HRP-II) antigen of Plasmodium falciparum in human blood was done using The SD BIOLINE Malaria Ag P.f test kit (China).

\subsubsection{Microscopy}

Microscopic examination was done under oil immersion at 100x magnification. Thin smears were examined for malaria parasite species identification, and the number of asexual parasites per 200 white blood cells (WBC) on the thick smear was multiplied by the WBC count (8000) to obtain the parasite count per microlitre (ul).

\subsection{Haemoglobin concentration estimation}

Hemoglobin $(\mathrm{Hb})$ concentration of each sample was estimated using an automated hematology analyzer (Mindray; model BC-3000 Plus, China).

\subsection{Statistical analysis}

Data analysis was carried out using Statistical Package for Social sciences (SPSS) version 16.0 software. Continuous variables were compared using independent t-test and categorical variables compared using chi square model. Logistic regression was used to identify factors associated with malaria parasitaemia and low birth weight. $\mathrm{P}<0.05$ was considered statistically significant.

\section{Results}

Table 1 General characteristics of study participants

\begin{tabular}{|c|c|c|c|}
\hline \multicolumn{2}{|c|}{ Parameters } & \multirow{2}{*}{$\begin{array}{l}\text { Number } \\
19\end{array}$} & \multirow{2}{*}{$\begin{array}{l}\text { Percentage (\%) } \\
19.0\end{array}$} \\
\hline Age group & $<20$ & & \\
\hline & $20-29$ & 57 & 57.0 \\
\hline & $30-39$ & 21 & 21.0 \\
\hline & $\geq 40$ & 3 & 3.0 \\
\hline \multirow{3}{*}{ Occupation } & Unemployed & 24 & 24.0 \\
\hline & Formal & 9 & 9.0 \\
\hline & Informal & 67 & 67.0 \\
\hline \multirow[t]{5}{*}{ Education } & None & 2 & 2.0 \\
\hline & Primary & 10 & 10.0 \\
\hline & JHS & 61 & 61.0 \\
\hline & SHS & 21 & 21.0 \\
\hline & Tertiary & 6 & 6.0 \\
\hline \multirow[t]{3}{*}{ Parity } & Nulliparous & 35 & 35.0 \\
\hline & Primiparous & 27 & 27.0 \\
\hline & Multipara & 38 & 38.0 \\
\hline \multirow[t]{3}{*}{ Gravidity } & Primigravida & 33 & 33.0 \\
\hline & Secundigravida & 25 & 25.0 \\
\hline & Multigravida & 42 & 42.0 \\
\hline \multirow[t]{2}{*}{ ITN } & Yes & 86 & 86.0 \\
\hline & No & 14 & 14.0 \\
\hline \multirow[t]{4}{*}{ SP } & 2 & 32 & 32.0 \\
\hline & 3 & 44 & 44.0 \\
\hline & 4 & 12 & 12.0 \\
\hline & 5 & 12 & 12.0 \\
\hline \multirow[t]{3}{*}{ Birth weight (Kg) } & $1.5-2.4$ & 14 & 14.0 \\
\hline & $2.4-2.9$ & 22 & 22.0 \\
\hline & $\geq 3.0$ & 64 & 64.0 \\
\hline \multirow[t]{2}{*}{ HB (g/dl) } & $<11$ & 27 & 27.0 \\
\hline & $\geq 11$ & 73 & 73.0 \\
\hline
\end{tabular}

JHS: Junior High School; SHS: Senior High School; ITN: Insecticide treated net; HB: Haemoglobin 
Majority of the study participants were in their third decade of life, had JHS education and had informal occupation. ITN and SP were used by $86 \%$ and $44 \%$ of the participants respectively. Anemia was present in $27 \%$ of the participants, with $14 \%$ giving birth to children with low birth weight (Table 1). Malaria was present in 19\% of the study participants when both RDT and microscopy were used (Table 2).

Table 2 Prevalence of malaria parasitaemia among study participants

\begin{tabular}{lcc}
\hline Parameters & Number & $\begin{array}{l}\text { Percentage } \\
(\%)\end{array}$ \\
\hline RDT & 19 & 19.0 \\
Positive & 81 & 81.0 \\
Negative & & \\
Microscopy & 19 & 19.0 \\
MPs Seen & 81 & 81.0 \\
No MPs seen & RDT: Rapid Diagnostic Test
\end{tabular}

Table 3 presents socio-demographic and clinical characteristics of participants stratified by malaria status. Most of the participants with malaria parasitaemia were in their third decade of life, primiparous, primigravida and not using ITN. Also, most of the infected participants had taken 3 doses of SP and had low HB concentration.

Table 3 Socio-demographic and clinical characteristics of participants stratified by malaria status

\begin{tabular}{|c|c|c|c|}
\hline Parameters & $\begin{array}{l}\text { Parasitaemic } \\
(\mathrm{N}=19)\end{array}$ & $\begin{array}{l}\text { Non-Parasitaemic } \\
(\mathrm{N}=81)\end{array}$ & P-value \\
\hline Age & $25.2 \pm 7.3$ & $25.8 \pm 6.4$ & 0.692 \\
\hline Age group & & & 0.386 \\
\hline$<20$ & $6(31.6)$ & $13(16.0)$ & \\
\hline $20-29$ & $9(47.4)$ & $48(59.3)$ & \\
\hline $30-39$ & $3(15.8)$ & $18(22.2)$ & \\
\hline$\geq 40$ & $1(5.3)$ & $2(2.5)$ & \\
\hline Occupation & & & 0.634 \\
\hline Unemployed & $6(31.6)$ & $18(22.2)$ & \\
\hline Formal & $2(10.5)$ & $7(8.6)$ & \\
\hline Informal & $11(57.9)$ & $56(69.1)$ & \\
\hline Education & & & 0.485 \\
\hline None & $0(0.0)$ & $2(2.5)$ & \\
\hline Primary & $0(0.0)$ & $10(12.3)$ & \\
\hline JHS & $14(73.7)$ & 47 (58.0) & \\
\hline SHS & $4(21.1)$ & $17(21.0)$ & \\
\hline Tertiary & $1(5.3)$ & $5(6.2)$ & \\
\hline Parity & & & 0.556 \\
\hline Nulliparous & $6(31.6)$ & $29(35.8)$ & \\
\hline Primiparous & 7 (36.8) & $20(24.7)$ & \\
\hline Multipara & $6(31.6)$ & $32(39.5)$ & \\
\hline Gravidity & & & 0.180 \\
\hline Primigravida & $9(47.4)$ & $24(29.6)$ & \\
\hline Secundigravida & $2(10.5)$ & $23(28.4)$ & \\
\hline Multigravida & $8(42.1)$ & $34(42.0)$ & \\
\hline ITN & & & 0.628 \\
\hline Yes & $2(10.5)$ & $12(14.8)$ & \\
\hline No & $17(89.5)$ & $69(85.2)$ & \\
\hline SP & & & 0.026 \\
\hline 2 & $4(21.1)$ & $28(34.6))$ & \\
\hline 3 & $14(73.7)$ & $30(37.0)$ & \\
\hline 4 & $0(0.0)$ & $12(14.8)$ & \\
\hline 5 & $1(5.3)$ & $11(13.6)$ & \\
\hline Birth weight (Kg) & & & 0.868 \\
\hline $1.5-2.4$ & $2(10.5)$ & $12(14.8)$ & \\
\hline $2.4-2.9$ & $4(21.1)$ & $18(22.2)$ & \\
\hline$\geq 3.0$ & $13(68.4)$ & $51(63.0)$ & \\
\hline Gestation (weeks) & $38.9 \pm 2.5$ & $38.2 \pm 3.9$ & 0.464 \\
\hline HB (g/dl) & $11.08 \pm 1.94$ & $11.97 \pm 1.71$ & 0.050 \\
\hline
\end{tabular}


Table 4 presents the socio-demographic and clinical characteristics of participants stratified by severity of parasitaemia. Severe parasitaemia was most prevalent among primigravida participants and those who are not using ITN. Half (50\%) of participants with severe parasitaemia gave birth to children with low birth weight. Birth weight was associated with severity of parasitaemia $(\mathrm{P}=0.029)$.

Table 4 Socio-demographic and clinical characteristics of participants stratified by severity of parasitaemia

\begin{tabular}{|c|c|c|c|c|}
\hline \multirow[b]{2}{*}{ Parameters } & \multicolumn{4}{|c|}{ Severity of parasitaemia } \\
\hline & $\begin{array}{l}\text { Mild } \\
(\mathrm{N}=10)\end{array}$ & $\begin{array}{l}\text { Moderate } \\
(\mathrm{N}=5)\end{array}$ & $\begin{array}{l}\text { Severe } \\
(N=4)\end{array}$ & P-value \\
\hline Age (years) & $26.5 \pm 7.3$ & $24.8 \pm 8.6$ & $22.5 \pm 6.6$ & 0.666 \\
\hline Age group & & & & 0.788 \\
\hline$<20$ & $2(20.0)$ & $2(40.0)$ & $2(50.0)$ & \\
\hline $20-29$ & $6(60.0)$ & $2(40.0)$ & $1(25.0)$ & \\
\hline $30-39$ & $1(10.0)$ & $1(20.0)$ & $1(25.0)$ & \\
\hline$\geq 40$ & $1(10.0)$ & $0(0.0)$ & $0(0.0)$ & \\
\hline Occupation & & & & 0.817 \\
\hline Unemployed & $3(30.0)$ & $2(40.0)$ & $1(25.0)$ & \\
\hline Formal & $1(10.0)$ & $0(0.0)$ & $1(25.0)$ & \\
\hline Informal & $6(60.0)$ & $3(60.0)$ & $2(50.0)$ & \\
\hline Education & & & & 0.199 \\
\hline None & $0(0.0)$ & $0(0.0)$ & $0(0.0)$ & \\
\hline Primary & $0(0.0)$ & $0(0.0)$ & $0(0.0)$ & \\
\hline JHS & $7(70.0)$ & $5(100.0)$ & $2(50.0)$ & \\
\hline SHS & $3(30.0)$ & $0(0.0)$ & $1(25.0)$ & \\
\hline Tertiary & $0(0.0)$ & $0(0.0)$ & $1(25.0)$ & \\
\hline Parity & & & & 0.467 \\
\hline Nulliparous & $2(20.0)$ & $2(40.0)$ & $2(50.0)$ & \\
\hline Primiparous & $5(50.0)$ & $2(40.0)$ & $0(0.0)$ & \\
\hline Multipara & $3(30.0)$ & $1(20.0)$ & $2(50.0)$ & \\
\hline Gravidity & & & & 0.718 \\
\hline Primigravida & $4(40.0)$ & $2(40.0)$ & $3(75.0)$ & \\
\hline Secundigravida & $1(10.0)$ & $1(20.0)$ & $0(0.0)$ & \\
\hline Multigravida & $5(50.0)$ & $2(40.0)$ & $1(25.0)$ & \\
\hline ITN & & & & 0.366 \\
\hline Yes & $2(20.0)$ & $0(0.0)$ & $0(0.0)$ & \\
\hline No & $8(80.0)$ & $5(100.0)$ & $4(100.0)$ & \\
\hline SP & & & & 0.538 \\
\hline 2 & $2(20.0)$ & $2(40.0)$ & $0(0.0)$ & \\
\hline 3 & $7(70.0)$ & $3(60.0)$ & $4(100.0)$ & \\
\hline 4 & $0(0.0)$ & $0(0.0)$ & $0(0.0)$ & \\
\hline 5 & $1(10.0)$ & $0(0.0)$ & $0(0.0)$ & \\
\hline Birth weight (Kg) & & & & 0.029 \\
\hline $1.5-2.4$ & $0(0.0)$ & $0(0.0)$ & $2(50.0)$ & \\
\hline $2.4-2.9$ & $3(30.0)$ & $0(0.0)$ & $1(25.0)$ & \\
\hline$\geq 3.0$ & $7(70.0)$ & $5(100.0)$ & $1(25.0)$ & \\
\hline Birth weight (Kg) & $3.43 \pm 0.67$ & $3.36 \pm 0.36$ & $2.65 \pm 0.57$ & 0.103 \\
\hline Gestation (weeks) & $39.4 \pm 2.0$ & $38.8 \pm 2.6$ & $37.8 \pm 3.6$ & 0.553 \\
\hline HB (g/dl) & $10.1 \pm 1.7$ & $12.8 \pm 1.5$ & $11.5 \pm 1.5$ & 0.022 \\
\hline
\end{tabular}

Table 5 shows the correlation of demographic and clinical characteristics of participants. Age had a significant positive correlation with parity, gravidity and birth weight. Parity and gravidity also had a significant positive correlation with 
birth weight, and $\mathrm{Hb}$ concentration significantly correlated with parasite density. Parasite density had an inverse correlation with birth weight, but not significant $(\mathrm{P}>0.05)$.

Table 5 Correlation of demographic and clinical characteristics of participants

\begin{tabular}{|c|c|c|c|c|c|c|c|c|}
\hline & & Age & Gestation & Parity & Gravidity & B wt & PD & HB \\
\hline \multirow[t]{2}{*}{ Age } & $\mathrm{R}$ & 1 & -0.01 & 0.779 & 0.784 & 0.198 & -0.151 & -0.061 \\
\hline & P-value & & 0.915 & 0.000 & 0.000 & 0.048 & 0.131 & 0.544 \\
\hline \multirow{2}{*}{ Gestation } & $\mathrm{R}$ & & 1 & 0.019 & 0.020 & 0.192 & -0.103 & -0.073 \\
\hline & P-value & & & 0.843 & 0.843 & 0.055 & 0.303 & 0.467 \\
\hline \multirow[t]{2}{*}{ Parity } & $\mathrm{R}$ & & & 1 & 0.949 & 0.211 & -0.131 & -0.081 \\
\hline & P-value & & & & 0.000 & 0.034 & 0.192 & 0.420 \\
\hline \multirow[t]{2}{*}{ Gravidity } & $\mathrm{R}$ & & & & 1 & 0.219 & -0.096 & -0.125 \\
\hline & P-value & & & & & 0.027 & 0.338 & 0.215 \\
\hline \multirow[t]{2}{*}{ B wt } & $\mathrm{R}$ & & & & & 1 & -0.152 & -0.005 \\
\hline & P-value & & & & & & 0.130 & 0.957 \\
\hline \multirow[t]{2}{*}{ PD } & $\mathrm{R}$ & & & & & & 1 & 0.035 \\
\hline & P-value & & & & & & & 0.728 \\
\hline HB & $\mathrm{R}$ & & & & & & & 1 \\
\hline
\end{tabular}

B wt: Birth weight

Table 6 shows a multinomial logistic regression of factors associated with malaria parasitaemia.

Table 6 Logistic regression of factors associated with malaria parasitaemia

\begin{tabular}{|c|c|c|c|c|}
\hline \multicolumn{2}{|c|}{ Parameters } & OR & $95 \%$ CI & P-value \\
\hline \multirow[t]{4}{*}{ Age group } & $<20$ & Ref & & \\
\hline & $20-29$ & 0.406 & $0.122-1.350$ & 0.142 \\
\hline & $30-39$ & 0.361 & $0.076-1.716$ & 0.200 \\
\hline & $\geq 40$ & 1.083 & $0.081-14.412$ & 0.952 \\
\hline \multirow[t]{3}{*}{ Occupation } & Unemployed & Ref & & \\
\hline & Formal & 0.857 & $0.138-5.306$ & 0.868 \\
\hline & Informal & 0.589 & $0.191-1.820$ & 0.358 \\
\hline \multirow[t]{5}{*}{ Education } & None & Ref & & \\
\hline & Primary & 1.000 & - & 1.000 \\
\hline & JHS & 1.117 & $1.02-1.504$ & 0.000 \\
\hline & SHS & 8.827 & 7.947-9.804 & 0.000 \\
\hline & Tertiary & 7.503 & - & - \\
\hline \multirow[t]{3}{*}{ Parity } & Nulliparous & Ref & & \\
\hline & Primiparous & 1.692 & $0.494-5.789$ & 0.402 \\
\hline & Multipara & 0.906 & $0.263-3.126$ & 0.876 \\
\hline \multirow[t]{3}{*}{ Gravidity } & Primigravida & Ref & & \\
\hline & Secundigravida & 0.232 & $0.045-1.190$ & 0.080 \\
\hline & Multigravida & 0.627 & $0.212-1.859$ & 0.400 \\
\hline \multirow[t]{2}{*}{ ITN } & Yes & 1.478 & $0.302-7.236$ & 0.630 \\
\hline & No & & & \\
\hline \multirow[t]{4}{*}{ SP } & 2 & Ref & & \\
\hline & 3 & 3.267 & $0.960-11.117$ & 0.058 \\
\hline & 4 & 0.000 & - & - \\
\hline & 5 & 0.636 & $0.064-6.345$ & 0.636 \\
\hline \multirow[t]{3}{*}{ Birth weight (Kg) } & $1.5-2.4$ & 0.654 & $0.130-3.291$ & 0.606 \\
\hline & $2.4-2.9$ & 0.872 & $0.252-3.021$ & 0.829 \\
\hline & $\geq 3.0$ & Ref & & \\
\hline \multirow[t]{2}{*}{ HB (g/dl) } & $<11$ & 1.779 & $0.616-5.136$ & 0.287 \\
\hline & $\geq 11$ & Ref & & \\
\hline
\end{tabular}

Participants less than 30 years and those with multigravida were more likely to give birth to children with low birth weight (Table 7). 
Asamoah et al. / GSC Biological and Pharmaceutical Sciences 2018, 04(02), 007-016

Table 7 Logistic regression of factors associated with low birth weight

\begin{tabular}{|c|c|c|c|c|}
\hline Parameters & & OR & $95 \% \mathrm{CI}$ & P-value \\
\hline \multirow[t]{4}{*}{ Age group } & $<20$ & 1.955 & $0.494-6.52$ & 0.000 \\
\hline & $20-29$ & 8.939 & $1.04-7.620$ & 0.000 \\
\hline & $30-39$ & 2.738 & - & - \\
\hline & $\geq 40$ & Ref & & \\
\hline \multirow[t]{3}{*}{ Occupation } & Unemployed & Ref & & \\
\hline & Formal & 1.900 & $0.347-10.404$ & 0.459 \\
\hline & Informal & 0.374 & $0.103-1.363$ & 0.136 \\
\hline \multirow[t]{5}{*}{ Education } & None & Ref & & \\
\hline & Primary & 1.870 & $0.012-2.256$ & 0.000 \\
\hline & JHS & 1.970 & $0.045-2.731$ & 0.000 \\
\hline & SHS & 6.610 & $0.014-8.800$ & 0.000 \\
\hline & Tertiary & 1.400 & - & - \\
\hline \multirow[t]{3}{*}{ Parity } & Nulliparous & Ref & & \\
\hline & Primiparous & 0.130 & $0.015-1.112$ & 0.062 \\
\hline & Multipara & 0.511 & $0.150-1.745$ & 0.284 \\
\hline \multirow[t]{3}{*}{ Gravidity } & Primigravida & Ref & & \\
\hline & Secundigravida & 0.364 & 0.087-1.518 & 0.165 \\
\hline & Multigravida & 0.133 & $0.027-0.669$ & 0.014 \\
\hline \multirow[t]{2}{*}{ Malaria status } & Parasitaemic & 0.676 & $0.138-3.311$ & 0.630 \\
\hline & Non-Parasitaemic & Ref & & \\
\hline \multirow[t]{2}{*}{ HB (g/dl) } & $<11$ & 0.407 & $0.085-1.950$ & 0.261 \\
\hline & $\geq 11$ & Ref & & \\
\hline
\end{tabular}

\section{Discussion}

Malaria in pregnancy is a major cause of anaemia, low birth weight and maternal death [10]. The WHO Roll Back Malaria recommends several strategies such as personal protection with insecticide impregnated bed nets (ITNs), intermittent preventive treatment (IPTp) and case management of anaemia and malaria illness with effective anti-malarial drugs to curb this menace. The prevalence of malaria among pregnant women in this study was 19\% when both rapid diagnostic test (RDT) kits and microscopy were used. This is similar to the $19.7 \%$ prevalence observed in a longitudinal study conducted among pregnant women at the Dangme-West district in the Greater Accra region of Ghana [8]. However, it is lower than the $47 \%$ and $5 \%$ prevalence rates recorded in longitudinal studies carried out at the Kassena-Nankana district [11] and at Madina in the Greater Accra region of Ghana [9] respectively. The differences in prevalence obtained could be attributed to changes in geographical locations, economic conditions and seasonal variations. Pregnant women are more susceptible to malaria due to the increased attractiveness to the vector, changes in immune system, placental sequestration and decreased parasite clearance.

Most studies have reported primigravida to have a higher prevalence of $P$. falciparum infection than women of higher gravidities, and an association of parity with malaria parasitaemia $[12,13]$. This is supported by the finding of most of the participants with malaria parasitaemia being primigravida and primiparous in our study. Also, it confirms the finding of severe parasitaemia being most prevalent among primigravida pregnant women. This may be due to the acquisition of immunity which decreases susceptibility to the infection [13]. 
The 14\% low birth weight observed among neonates of the pregnant women in this study is higher than the $3 \%$ reported by both [9] in Ghana and [14] in Southeast Nigeria. Half (50\%) of our study participants with severe parasitaemia gave birth to children with low birth weight, and birth weight was associated with severity of parasitaemia. The mechanism underlying the cause of low birth in malaria is not fully understood. A high density of parasites and chronic parasite infection in the placental blood and the associated cellular immune response may result in consumption of glucose and oxygen that would have gone to the fetus. Secondly, histopathological studies of infected placentas have found thickening of the cytotrophoblastic membranes, which may interfere with nutrient transport [3]. Furthermore, malariaassociated maternal anemia may also contribute independently to intra-uterine growth retardation, most likely through a reduction in oxygen transport to the fetus $[3,15]$.

Multigravida pregnant women were more likely to give birth to children with low birth weight. A high risk of low birth weight infants for multigravida are assumed to occur because those residing in low transmission areas have not acquired significant antimalarial immunity or because they are exposed to a high risk of human immunodeficiency virus (HIV) [16]. This is further supported by the finding of a significant positive correlation between gravidity and birth weight among the pregnant women.

Malaria parasitaemia during pregnancy has significant maternal and neonatal effects and outcomes. Although the vast majority of women with malaria infections during pregnancy remain asymptomatic, infection increases the risk of maternal anemia and delivering a low birth weight baby. Low birth weight is also a well-documented risk factor for poor neurosensory, cognitive, and behavioral development, as well as for limited school performance and academic achievement $[17,18]$. The effects on neonatal mortality are even more marked, with a low birth weight baby being nine times more likely to die in the first month of life than a normal-weight baby. There is therefore the need to intensify measures to curb this major public health problem. The use of malaria control and prevention methods such as ITN's needs to be intensified as most of the pregnant women with severe malaria parasitaemia were not using ITN. Also, measures should be taken to tackle the risk factors of low birth weight such as age less than 30 years and mulitigravidity observed in this study.

The study has certain limitations. Although maternal parasitaemia have been used routinely to detect malaria during pregnancy, it is recognized that peripheral parasitaemia may remain below the levels of microscopic detection while parasites are harbored by the placenta [19]. Histological examination of the placenta is the most sensitive indicator of maternal infection. This might have resulted in underestimation of the prevalence of malaria. Also, we could not assess all other factor that might contribute to low birth weight in parturient with malaria.

\section{Conclusion}

High malaria parasitaemia was found among parturient who have taken intermittent preventive treatment in pregnancy (IPTp) in this study. Low birth weight was prevalent among $14 \%$ neonates of the pregnant women, and severe parasitaemia was associated with low birth weight. The use of malaria control and prevention methods such as ITN's needs to be intensified since most of the pregnant women with severe malaria parasitaemia were not using ITN.

\section{Compliance with ethical standards}

\section{Acknowledgments}

The authors wish to thank all the parturient who approved to be enrolled onto the study, and the management of Bekwai Municipal Hospital and Akomaa Memorial SDA Hospital for their support.

\section{Disclosure of conflict of interest}

The authors declare that there are no competing interests.

\section{Statement of ethical approval}

Ethical approval was sought from the University of Cape Coast Institutional Review Board (UCCIRB) and the authorities of the various hospitals before commencing the study. Informed written consent was also sought from the pregnant women for participation and publication of findings from the study. 


\section{Statement of informed consent}

Informed consent was obtained from all individual participants included in the study.

\section{References}

[1] Opare-Addo HS and Odoi AT. (2002). Malaria in pregnancy. Accra: Asante and Hittscher, Printing Press Limited.

[2] Edzeamey FJ, Awuah M, Ako AK, Wiredu OK, Sampong BB, Gborgblorvor D, Yeboah EK and Suleiman A. (2018). Thrombocytopenia amongst patients: A comparison of malaria and non- malaria patients. International Journal of Pharmacy and Biological Sciences, 8(1), 303-307.

[3] Ismail MR, Ordi J, Menendez C, Ventura PJ, Aponte JJ, Kahigwa E, Hirt R, Cardesa A, and Alonso APL. (2000). Placental pathology in malaria: a histological, immunohistochemical, and quantitative study. Human Pathology, 31, 85-93.

[4] Feresu SA, Harlow SD and Woelk GB. (2004). Risk factors for prematurity at Harare Maternity Hospital, Zimbabwe. International Journal of Epidemiology, 33(6), 1194-1201.

[5] Guyatt HL and Snow RW. (2004). Impact of malaria during pregnancy on low birth weight in Sub-Saharan Africa. Clinical Microbiology Reviews, 17(4), 760-769.

[6] Afudego CE (2001). Strengthening institutions to improve public expenditure accountability: Cost effectiveness analysis of insecticide treated mosquito nets (ITNs) and indoor residual spraying (IRS)-malaria interventions in Ghana (Children under Five):1-6.

[7] World Health Organization. (2015). World malaria report 2014. World Health Organization.

[8] Ofori M, Ansah E, Agyepong I, Ofori-Adjei D, Hviid L and Akanmori B. (2009). Pregnancy-associated malaria in a rural community of Ghana. Ghana Medical Journal, 43(1), 13-18.

[9] Ofori MF, Quakyi IA, Wilson ML and Akanmori BD. (2014). Prevalence of peripheral blood parasitaemia, anaemia and low birth weight among pregnant women in a suburban area in coastal Ghana. Pan African Medical Journal, 17(1), 3.

[10] Boel ME, Rijken MJ, J. BB, Nosten F and McGready R. (2015). The epidemiology of postpartum malaria: a systematic review. Malaria Journal, 11, 144.

[11] Clerk CA, Bruce J, Greenwood B and Chandramohan D. (2009). The epidemiology of malaria among pregnant women attending antenatal clinics in an area with intense and highly seasonal malaria transmission in northern Ghana. Tropical Medicine and International Health, 14(6), 688-695.

[12] Falade CO, Tongo 00, Ogunkunle 00 and Orimadegun AE. (2010). Effects of malaria in pregnancy on newborn anthropometry. Journal of Infection in Developing Countries, 4(7), 448-453.

[13] Nosten F, McGready R and Mutabingwa T. (2007). Case management of malaria in pregnancy. The Lancet Infectious Diseases, 7, 118-125.

[14] Nwali MI, Ejikeme BN, Agboeze JJ, Onyebuchi AK and Anozie BO. (2015). Plasmodium falciparum parasitaemia among booked parturients who received two doses of sulfadoxine pyrimethamine (SP) for intermittent preventive treatment in pregnancy (IPTp) in a tertiary health facility Southeast Nigeria. Nigeria Medical Journal, 56(218-224), 218-224.

[15] Verhoeff FH, Brabin BJ, Buuren Sv, Chimsuku L, Kazembe P, Wit JM and Broadhead RL. (2001). An analysis of intra-uterine growth retardation in rural Malawi. European Journal of Clinical Nutrition, 55, 682-689.

[16] Brabin BJ, Agbaje SOF, Ahmed F and Briggs ND. (1999). A birth weight nomogram for Africa, as a malaria-control indicator. Annals of Tropical Medicine and Parasitology, 93, 43-57.

[17] Taylor HG, Klein N, Minich MN and Hack M. (2000). Middle-school age outcomes in children with very low birthweight. Child Development, 71, 1495-1511.

[18] Teplin SW, Burchinal M, Johnson-Martin N, Humphrey R and Kraybill E. (1991). Neurodevelopmental, health and growth status at age 6 years of children with birth weights less than 1001 grams. The Journal of Pediatrics, 118, 68-777.

[19] Shulman CE and Dorman EK. (2003). Reducing childhood mortality in poor countries. Importance and prevention of malaria in pregnancy. Transactions of The Royal Society of Tropical Medicine and Hygiene, 97, 30-35. 


\section{How to cite this article}

Asamoah GD, Adoba P, Edzeamey FJ, Ephraim RKD, Sampong BB, Gborgblorvor D and Wiredu OK. (2018). Asymptomatic malaria and its effect on parturients who received intermittent preventive treatment, a cross sectional study of the Bekwai District Ghana. GSC Biological and Pharmaceutical Sciences, 4(2), 07-16. 